\title{
Curcumin analogues with high activity for inhibiting human prostate cancer cell growth and androgen receptor activation
}

\author{
DAI-YING ZHOU ${ }^{1,2,3}$, NING DING ${ }^{3}$, ZHI-YUN DU $^{1}$, XIAO-XING CUI $^{3}$, HONG WANG $^{3}$, \\ XING-CHUAN WEI ${ }^{1}$, ALLAN H. CONNEY ${ }^{1,3}$, KUN ZHANG ${ }^{1}$ and XI ZHENG ${ }^{1,3}$ \\ ${ }^{1}$ Laboratory of Natural Medicinal Chemistry \& Green Chemistry, Guangdong University of Technology, Guangzhou, \\ Guangdong 510006; ${ }^{2}$ Guangdong Food and Drug Vocational College, Guangzhou, Guangdong 510520, P.R. China; \\ ${ }^{3}$ Department of Chemical Biology, Susan Lehman Cullman Laboratory for Cancer Research, \\ Ernest Mario School of Pharmacy, Rutgers, The State University of New Jersey, Piscataway, NJ 08854, USA
}

Received December 17, 2013; Accepted January 8, 2014

DOI: $10.3892 / \mathrm{mmr} .2014 .2380$

\begin{abstract}
The androgen receptor (AR) has a critical role in prostate cancer development and progression. Several curcumin analogues (A10, B10, C10, E10 and F10) with different linker groups were investigated for their effects in human prostate cancer CWR-22Rv1 and LNCaP cell lines. The ability of these compounds to inhibit testosterone (TT)- or dihydrotestosterone (DHT)-induced AR activity was determined by an AR-linked luciferase assay and by TT- or DHT-induced expression of prostate specific antigen. Compounds F10 and E10 had stronger inhibitory effects on the growth of cultured CWR-22Rv1 and LNCaP cell lines, and they also had enhanced stimulatory effects on apoptosis compared with curcumin and other curcumin analogues (A10, B10, C10) in CWR-22Rv1 cells. E10 and F10 were more potent inhibitors of AR activity than curcumin, A10 and B10. The higher activities of E10 and F10 may be correlated with a heteroatom linker. The results indicate that one of the potential mechanisms for the anticancer effect of the curcumin analogues was inhibition of AR pathways in human prostate cancer cells.
\end{abstract}

Correspondence to: Dr Kun Zhang, Laboratory of Natural Medicinal Chemistry \& Green Chemistry, Guangdong University of Technology, 100 Waihun Xi Road, Guangzhou, Guangdong 510006, P.R. China

E-mail:kzhang@gdut.edu.cn

Dr Xi Zheng, Department of Chemical Biology, Susan Lehman Cullman Laboratory for Cancer Research, Ernest Mario School of Pharmacy, Rutgers, The State University of New Jersey, 164 Frelinghuysen Road, Piscataway, NJ 08854, USA

E-mail: xizheng@pharmacy.rutgers.edu

Key words: prostate cancer, androgen receptor, curcumin analogues, prostate specific antigen

\section{Introduction}

Prostate cancer is the second leading cause of cancer-related mortality in American males (1). The androgen receptor (AR) is a ligand activated steroid hormone receptor and a key regulator of normal prostate development and function (2). The AR has a critical role in prostate cancer development and progression (3). Consequently, the current therapeutic strategies for prostate cancer intervention, including androgen ablation therapy, inhibits AR function (4). An aggressive form of prostate cancer therapy is based on a combination of androgen synthesis suppression and AR inhibition (5). Therefore, identification of chemical agents that inhibit AR signaling by known or novel mechanisms warrant further investigation for the development of a novel prostate cancer therapeutic approach.

Curcumin is a non-nutritive yellow pigment found in the spice turmeric, which is derived from the rhizome of the plant Curcuma longa Linn. Numerous studies have demonstrated the anticancer activity of curcumin and curcumin analogues in animal models (6-11), as well as growth inhibition and apoptosis-inductive effects in a variety of cancer cell lines in vitro (12-20). However, the clinical efficacy of curcumin is limited, which is likely due to its low bioavailability (21-23).

Our previous study reported on the synthesis and evaluation of 61 curcumin-related compounds for the inhibitory effects on cultured prostate cancer PC-3 cells, pancreas cancer Panc-1 cells and colon cancer HT-29 cells (24). Five of these curcumin analogues with different linker groups but identical symmetrical aromatic rings (as revealed in Fig. 1) were selected for further study. These compounds included (2E,6E)-2,6-bis(3,4,5-trimethoxybenzylidene) cyclohexanone (A10), (2E,5E)-2,5-bis(3,4,5-trimethoxybenzylidene) cyclopentanone (B10), (1E,4E)-1,5-bis(3,4,5-trimethoxyphenyl) penta-1,4-dien-3-one (C10), (3E,5E)-3,5-bis (3,4,5-trimethoxybenzyli-dene) tetrahydropyran-4-one (E10), (3E,5E)-3,5-bis (3,4,5-trimethoxybenzylidene) tetrahydrothiopyran-4-one (F10). Compounds with a heteroatom linker (compounds E10 and F10) demonstrated a stronger inhibitory effect than those without a heteroatom linker (compounds A10, B10 and C10) on 
the growth of human prostate cancer cells, although $\mathrm{C} 10$ had intermediate activity. It was also demonstrated that E10 and F10 more potently inhibited AR activity and testosterone (TT)- or dihydrotestosterone (DHT)-induced prostate specific antigen expression than A10, B10 and curcumin in CWR-22Rv1 cells.

\section{Materials and methods}

Chemistry. Several curcumin analogues (A10, B10, C10, E10, F10 as demonstrated in Fig. 1) with different linker groups were synthesized by coupling the appropriate substituted benzaldehyde with cyclohexanone, cyclopentanone, acetone, tetrahydropyran-4-ones or tetrahydrothiopyran-4-one as previously described (24). Characterization of the compounds, (2E,6E)-2,6-bis(3,4,5-trimethoxy-benzylidene) cyclohexanone (A10), (2E,5E)-2,5-bis(3,4,5-trimethoxybenzylidene) cyclopentanone (B10), (1E,4E)-1,5-bis(3,4,5-trimethoxyphenyl) penta-1,4-dien-3-one (C10), (3E,5E)-3,5-bis(3,4,5-trime thoxybenzylidene) tetrahydropyran-4-one (E10) and (3E,5E)-3,5-bis(3,4,5-trime-thoxybenzylidene) tetrahydro thiopyran-4-one (F10), was previously described in detail (24).

Cell culture and reagents. CWR-22Rv1 and LNCaP cells were obtained from the American Type Culture Collection (ATCC; Rockville, MD, USA). RPMI-1640 tissue culture medium, penicillin-streptomycin, L-glutamine and fetal bovine serum (FBS) were purchased from Gibco (Grand Island, NY, USA). CWR-22Rv1 cells were maintained in RPMI-1640 culture medium. RPMI-1640 medium was supplemented with $10 \%$ FBS, penicillin (100 units $/ \mathrm{ml})$-streptomycin $(100 \mu \mathrm{g} / \mathrm{ml})$ and L-glutamine $(300 \mu \mathrm{g} / \mathrm{ml})$. The cultured cells were grown at $37^{\circ} \mathrm{C}$ in a humidified atmosphere of $5 \% \mathrm{CO}_{2}$ and were passaged twice a week. Curcumin analogues were dissolved in dimethyl sulfoxide and the final concentration of DMSO was $0.1 \%$ in all experiments.

MTT, trypan blue and apoptosis assays. For the MTT assay, CWR-22Rv1 and LNCaP cells were seeded at a density of $2 \times 10^{4}$ cells $/ \mathrm{ml}$ of medium in a 96 -well plate $(0.2 \mathrm{ml} /$ well $)$ and incubated for $24 \mathrm{~h}$. The cells were then treated with various concentrations $(0.5-30 \mu \mathrm{M})$ of curcumin analogues for $72 \mathrm{~h}$. Following treatment, 3-[4,5-dimethylthiazol-2-yl]-2,5-diphenyltetrazoliumbromide was added to each well of the plate and incubated for $1 \mathrm{~h}$. After careful removal of the medium, $0.1 \mathrm{ml}$ DMSO was added to each well and absorbance at $550 \mathrm{~nm}$ was recorded on a microplate reader. For the trypan blue exclusion assay, the CWR-22Rv1 cells were seeded at a density of $2 \times 10^{4}$ cells $/ \mathrm{ml}$ of medium in $35 \mathrm{~mm}$ tissue culture dishes and incubated for $24 \mathrm{~h}$. The cells were then treated with curcumin analogues for $96 \mathrm{~h}$. The number of viable cells following each treatment was determined using a hemocytometer under a light microscope (Nikon Optiphot; Nikon, Tokyo, Japan). The cell viability was determined by the trypan blue exclusion assay, which was performed by mixing $80 \mu \mathrm{l}$ of the cell suspension and $20 \mu \mathrm{l}$ of $0.4 \%$ trypan blue stain solution for $2 \mathrm{~min}$. The blue cells were counted as dead cells and the cells that did not absorb dye were counted as live cells. Apoptosis was determined by morphological assessment in the cells stained with propidium iodide (25). Apoptotic cells were identified by classical morphological features, including nuclear condensation, cell shrinkage and the formation of apoptotic bodies. At least 200 cells were counted in each sample and the percentage of apoptotic cells was determined.

AR luciferase reporter assay. AR transcriptional activity was measured by an AR-luciferase reporter gene expression assay. An AR luciferase construct was stably transfected into CWR-22Rv1 cells and a single stable clone, CWR-22Rv1/AR, was used in the present study. CWR22-Rv-1 cells cultured in 10\% FBS RPMI-1640 medium were infected with a lentivirus carrying the Cignal Lenti AR reporter (luciferase; Qiagen, Valencia, CA, USA) in the medium containing $8 \mu \mathrm{g} / \mathrm{ml}$ Polybrene (Sigma, St. Louis, MO, USA). At $6 \mathrm{~h}$ following infection, the culture medium was replaced with fresh $10 \%$ RPMI-1640 medium. To establish the cells expressing stable AR-luciferase reporter, cells were selected using puromycin (5 $\mu \mathrm{g} / \mathrm{ml})$ on day 3 following infection for one week. The selected cells were then used for the reporter assay for AR activity.

The CWR-22Rv1/AR cells were treated with curcumin and its analogues for $24 \mathrm{~h}$, and the luciferase activities were measured using luciferase assay kits from Promega Corporation (Madison, WI, USA). Following treatment, the cells were washed with ice-cold phosphate-buffered saline (PBS) and harvested in a reporter lysis buffer. After centrifugation, $10 \mu \mathrm{l}$ aliquots of the supernatants were used for measuring the luciferase activity with a luminometer from Turner Designs Instruments (Sunnyvale, CA, USA). The luciferase activity was normalized against protein concentration and expressed as the percentage of luciferase activity in the control cells, which were treated with DMSO solvent. The protein level was determined by Bio-Rad protein assay kits (Bio-Rad, Hercules, CA, USA) according to the manufacturer's instructions.

Western blot analysis. Following treatment with curcumin, A10, B10, C10, E10 and F10 for $24 \mathrm{~h}$, the CWR-22Rv1 and LNCaP cells were washed with ice-cold PBS and lysed with $800 \mu \mathrm{l}$ of lysis buffer $(10 \mathrm{~mm}$ Tris- $\mathrm{HCl}, \mathrm{pH} 8.0,10 \mathrm{~mm}$ EDTA, $150 \mathrm{~mm}$ sodium chloride, 1\% NP-40, 0.5\% SDS, in deionized water). The homogenates were centrifuged at $12,000 \mathrm{x} \mathrm{g}$ for $15 \mathrm{~min}$ at $4^{\circ} \mathrm{C}$. The protein concentration of whole cell lysates was determined with a Bio-Rad protein assay kit (Bio-Rad). Equal amounts $(50 \mu \mathrm{g})$ of protein were then resolved on a $10 \%$ Criterion Precast Gel (Bio-Rad) and transferred onto a PVDF membrane using a semi-dry transfer system. The membrane was then probed with anti-PSA (Santa Cruz Biotechnology, Inc., Santa Cruz, CA, USA) primary antibody. Following hybridization with primary antibody, the membrane was washed with Tris-buffered saline (TBS) three times, then incubated with horseradish peroxidase-conjugated secondary antibody (Santa Cruz Biotechnology, Inc.) and washed with TBS three times. Final detection was performed with enhanced chemiluminescent reagents. The extent of protein loading was determined by blotting for $\beta$-actin. The membrane was incubated in stripping buffer (100 mm $\beta$-mercaptoethanol, 2\% SDS and $62.5 \mathrm{~mm}$ Tris- $\mathrm{HCl}$ at $\mathrm{pH} 6.7$ ) at $50^{\circ} \mathrm{C}$ for $30 \mathrm{~min}$ with occasional agitation prior to incubating in blocking buffer and re-probing using anti- $\beta$-actin (Santa Cruz Biotechnology, Inc.). 
<smiles>COc1cc(/C=C/C(=O)CC(=O)/C=C/c2ccc(O)c(OC)c2)ccc1O</smiles>

(E,E)-1,7-Bis(4-hydroxy-3-methoxyphenyl)-1,6-heptadiene-3,5-dione Curcumin<smiles>COc1cc(C=C2CCC(=Cc3cc(OC)c(OC)c(OC)c3)C2=O)cc(OC)c1OC</smiles>

(2E,5E)-2,5-Bis (3,4,5-trimethoxybenzylidene)cyclopentanone B10<smiles>COc1cc(/C=C2\COC/C(=C\c3cc(OC)c(OC)c(OC)c3)C2=O)cc(OC)c1OC</smiles>

(3E,5E)-3,5-Bis(3,4,5-trimethoxybenzylidene)tetrahydropyran-4-one E10<smiles>COc1cc(/C=C2\CCC/C(=C\c3cc(OC)c(OC)c(OC)c3)C2=O)cc(OC)c1OC</smiles>

(2E,6E)-2,6-Bis (3,4,5-trimethoxybenzylidene)cyclohexanone A10<smiles>COc1cc(/C=C/C(=O)/C=C/c2cc(OC)c(OC)c(OC)c2)cc(OC)c1OC</smiles>

(1E,4E)-1,5-Bis (3,4,5-trimethoxyphenyl) penta-1,4-dien-3-one $\mathrm{C} 10$<smiles>COc1cc(/C=C2\CSC/C(=C\c3cc(OC)c(OC)c(OC)c3)C2=O)cc(OC)c1OC</smiles>

(3E,5E)-3,5-Bis(3,4,5-trimethoxybenzylidene)tetrahydrothiopyran-4-one F10

Figure 1. Structures of curcumin and its analogues.

Statistical analyses. The analyses of differences among curcumin and its analogues on the TT- or DHT-induced activation of AR were based on a repeated measurement model. The effects of the treatments were assessed by comparing the rates of change over time between the treatment groups (i.e., comparing the slopes between the treatment groups). The analysis of variance (ANOVA) method with the Tukey-Kramer test was used for the comparison of effects among the different treatment groups at the end of the study. $\mathrm{P}<0.05$ was considered to indicate a statistically significant difference.

\section{Results}

Effects of curcumin and its analogues on CWR-22Rv1 and LNCaP cells. The inhibitory effects of curcumin analogues on the growth of cultured CWR-22Rv1 and LNCaP cells were determined by using MTT and trypan blue exclusion assays. For each incubation, curcumin was examined as a positive control. The inhibitory effects of different concentrations of curcumin and its analogues in cultured CWR-22Rv1 and LNCaP cells are presented in Fig. 2. All of the compounds had stronger inhibitory effects than curcumin as determined by the MTT assay. Among the five curcumin analogues tested in the present study, compounds E10, F10 and C10 exhibited the most potent inhibitory effects on the growth of cultured CWR-22Rv1 and LNCaP cells. The $\mathrm{IC}_{50}$ values for E10 and F10 were lower than $1 \mu \mathrm{M}$ in the CWR-22Rv1 and LNCaP cells, indicating that these compounds were $\sim 20$-fold more active than curcumin $\left(\mathrm{IC}_{50}=16.99 \mu \mathrm{M}\right)$. As demonstrated in Table I, the $\mathrm{IC}_{50}$ values of the five curcumin analogues ranged from 0.82 to $13.62 \mu \mathrm{M}$. The numbers of viable and dead cells were determined by the trypan blue exclusion assay following treatment of the CWR-22Rv1 cells with curcumin and its analogues for $96 \mathrm{~h}$. As demonstrated in Table II, a reduction in the number of viable cells were observed. Compared with the control group, the numbers of viable cells in the various groups treated with curcumin and its analogues were decreased by $15.4 \%$ to $95.4 \%$ (Table II). The effects of curcumin and its analogues on apoptosis of CWR-22Rv1 cells were determined by morphological assessment in the propidium iodide stained cells. In these studies, the CWR-22Rv1 cells were treated with curcumin and its analogues for $96 \mathrm{~h}$. As demonstrated in Table II, weak inhibitory effects on growth and weak stimulatory effects on the induction of apoptosis of CWR-22Rv1 cells were observed by treatment with A10 $(1 \mu \mathrm{M})$ and B10 $(1 \mu \mathrm{M})$, while more evident effects were observed by treatment with E10 $(0.5 \mu \mathrm{M})$ and F10 $(0.5 \mu \mathrm{M})$. C10 $(1 \mu \mathrm{M})$ had a moderate inhibitory effect on growth and a moderate stimulatory effect on apoptosis.

Effects of curcumin and its analogues on AR activity in CWR-22Rv1/AR cells. An AR-luciferase reporter gene expression assay in CWR-22Rv1/AR cells was utilized to determine the effect of curcumin and its analogues on the TT- or DHT-induced activation of AR. Cultured CWR-22Rv1/AR cells were treated with TT in combination with curcumin analogues $(1 \mu \mathrm{M})$ for $24 \mathrm{~h}$. As demonstrated in Fig. 3, a marginal inhibitory effect on the TT- or DHT-induced increase in AR activity was observed in the cultured CWR-22Rv1/AR cells treated with curcumin $(1 \mu \mathrm{M}), \mathrm{A} 10(1 \mu \mathrm{M})$ or B10 $(1 \mu \mathrm{M})$, while more evident inhibitory effects were observed in the CWR-22Rv1/AR cells treated with $\mathrm{C} 10(1 \mu \mathrm{M}), \mathrm{E} 10(1 \mu \mathrm{M})$ and $\mathrm{F} 10(1 \mu \mathrm{M})$. Statistical analysis using ANOVA with the Tukey's multiple comparison 
A

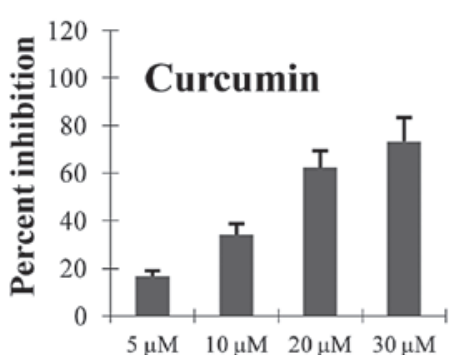

Concentration

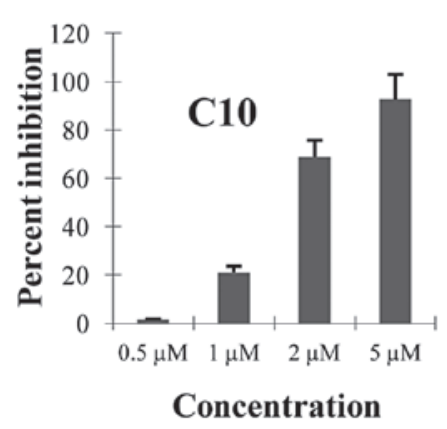

B

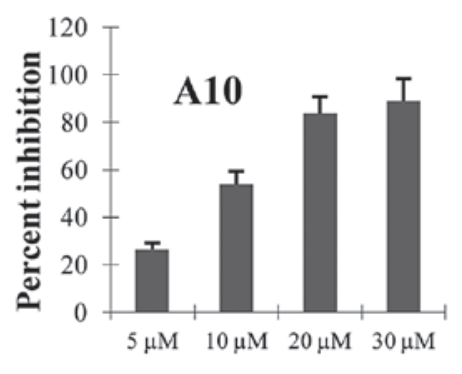

Concentration

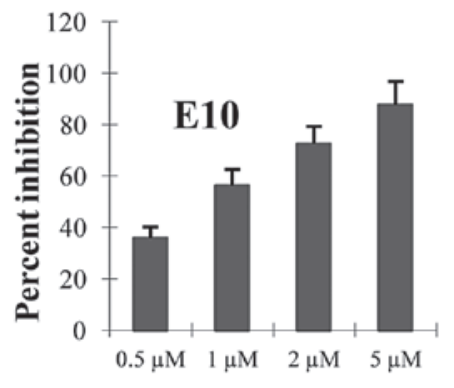

Concentration
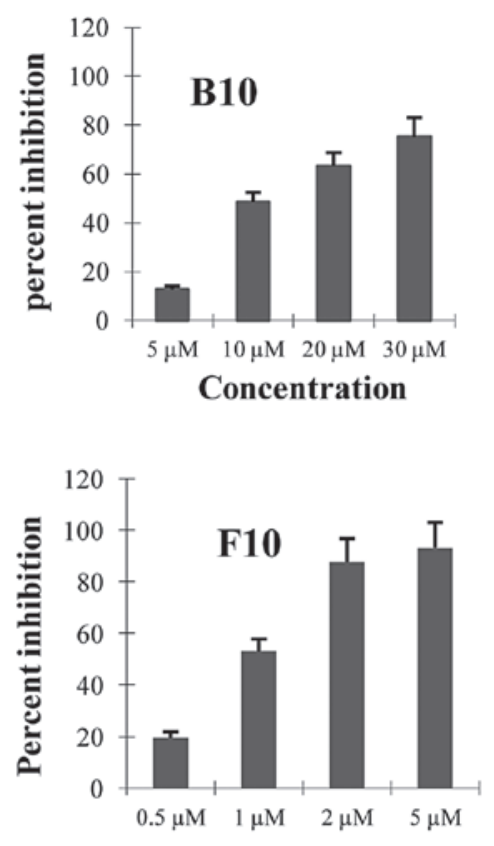

Concentration

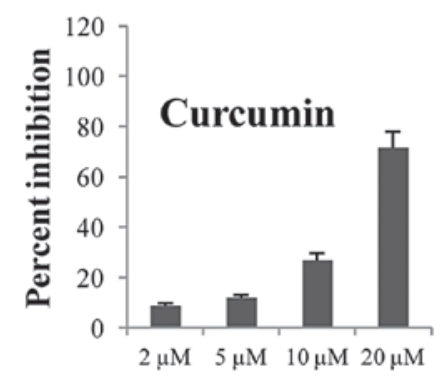

Concentration

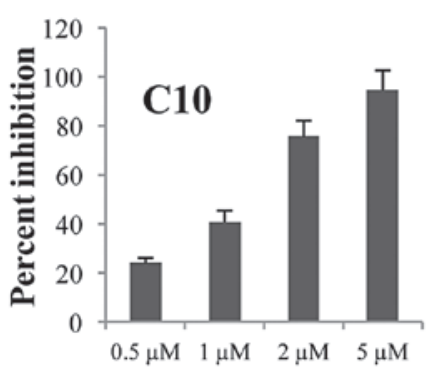

Concentration

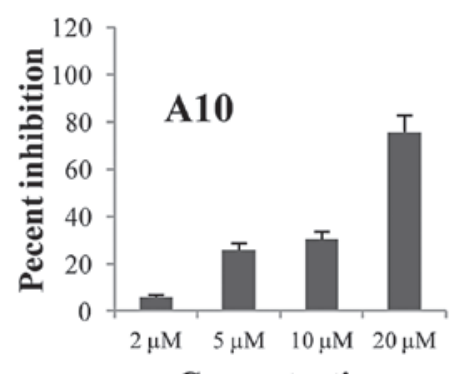

Concentration

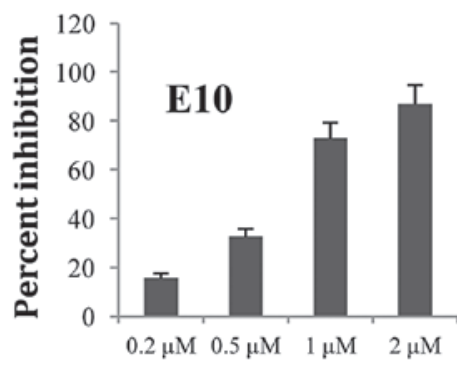

Concentration
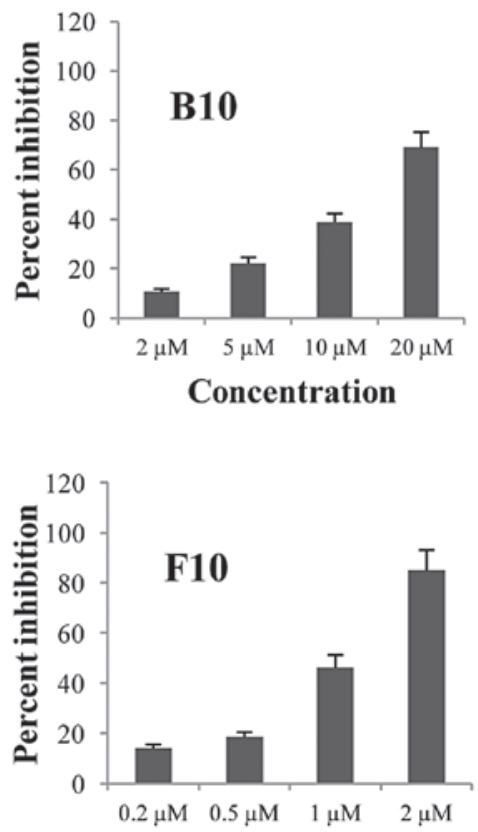

Concentration

Figure 2. Inhibitory effects of curcumin analogues on the growth of (A) CWR-22Rv1 and (B) LNCaP cells. Prostate cancer CWR-22Rv1 and LNCaP cells were seeded at a density of $2 \times 10^{4}$ cells $/ \mathrm{ml}$ of medium in 96 -well plates $(0.2 \mathrm{ml} /$ well $)$ and incubated for $24 \mathrm{~h}$. The cells were then treated with various concentrations $(0.2-30 \mu \mathrm{M})$ of the different compounds for $72 \mathrm{~h}$. (A and B) The effects of the different compounds on the growth of CWR-22Rv1 and LNCaP cells were determined by the MTT assay. Each value represents the mean \pm standard error from three separate experiments.

tests demonstrated that AR activity was significantly lower in the cells treated with group $\mathrm{C} 10, \mathrm{E} 10$ and F10 compounds than in the cells treated with curcumin or A10 and B10. $\mathrm{P}<0.001$ for control vs. TT $($ DHT $)+$ CUR, TT $($ DHT $)+$ A10 or TT $($ DHT $)+$ B10; $\mathrm{P}<0.001$ for TT $(\mathrm{DHT})$ vs. TT $(\mathrm{DHT})+\mathrm{A} 10, \mathrm{TT}(\mathrm{DHT})+\mathrm{B} 10$, TT $($ DHT $)+$ C10, TT $($ DHT $)+$ E10 or TT $($ DHT $)+$ F10; P<0.001 for TT $($ DHT $)+$ CUR vs. TT $($ DHT $)+$ C10, TT $($ DHT $)+$ E10 or TT $(\mathrm{DHT})+\mathrm{F} 10 ; \mathrm{P}<0.001$ for TT $(\mathrm{DHT})+\mathrm{A} 10$ vs. TT $(\mathrm{DHT})+\mathrm{C} 10$,
TT $(\mathrm{DHT})+\mathrm{E} 10$ or TT $(\mathrm{DHT})+\mathrm{F} 10 ; \mathrm{P}<0.001$ for TT $(\mathrm{DHT})+$ B10 vs. TT $($ DHT $)+$ C10, TT $($ DHT $)+$ E10 or TT $($ DHT $)+$ F10.

Effects of curcumin and its analogues on the expression of PSA in CWR-22Rv1 and LNCaP cells. The levels of PSA were evaluated by western blot analysis using an anti-PSA antibody. The cultured CWR-22Rv1 and LNCaP cells were treated with TT, DHT and curcumin analogues A10, B10, C10, E10 or F10 for 
Table I. Inhibitory effects of curcumin and its analogues on the growth of CWR-22Rv1 cells.

\begin{tabular}{lrr}
\hline & \multicolumn{2}{c}{$\mathrm{IC}_{50}(\mu \mathrm{M})$} \\
\cline { 2 - 3 } Compound & \multicolumn{1}{c}{ CWR-22Rv1 } & \multicolumn{1}{c}{ LNCaP } \\
\hline Curcumin & $16.99 \pm 3.0$ & $13.59 \pm 1.8$ \\
A10 & $8.76 \pm 0.5$ & $9.8 \pm 1.2$ \\
B10 & $13.62 \pm 2.0$ & $11.4 \pm 1.5$ \\
C10 & $1.78 \pm 0.2$ & $1.07 \pm 0.2$ \\
E10 & $0.82 \pm 0.1$ & $0.65 \pm 0.2$ \\
F10 & $0.96 \pm 0.1$ & $0.81 \pm 0.2$ \\
\hline
\end{tabular}

Prostate cancer CWR-22Rv1 cells were seeded at a density of $2 \times 10^{4}$ cells $/ \mathrm{ml}$ of medium in 96 -well plates $(0.2 \mathrm{ml} /$ well $)$ and incubated for $24 \mathrm{~h}$. The cells were then treated with various concentrations $(0.1-20 \mu \mathrm{M})$ of the different compounds for $72 \mathrm{~h}$. The effects of the different compounds on the growth of CWR-22Rv1 cells were determined by an MTT assay. Each value represents the mean \pm standard error from three separate experiments.
Table II. Effects of curcumin and its analogues on the growth of CWR-22Rv1 cells.

Treatment No. of viable cells $\left(1 \times 10^{-4}\right)$ Percent apoptotic cells

\begin{tabular}{lrr}
\hline Control & $43.1 \pm 1.4$ & $1.7 \pm 0.2$ \\
Curcumin & $36.4 \pm 1.5$ & $2.3 \pm 0.3$ \\
A10 & $30.5 \pm 1.3$ & $4.7 \pm 0.9$ \\
B10 & $33.0 \pm 1.0$ & $3.1 \pm 0.3$ \\
C10 & $12.4 \pm 0.9$ & $7.6 \pm 0.5$ \\
E10 & $8.5 \pm 0.8$ & $22.8 \pm 1.0$ \\
F10 & $2.0 \pm 0.3$ & $29.4 \pm 2.1$ \\
\hline
\end{tabular}

Prostate cancer CWR-22Rv1 cells were seeded at a density of $2 \times 10^{4}$ cells $/ \mathrm{ml}$ in $35 \mathrm{~mm}$ tissue culture dishes and incubated for $24 \mathrm{~h}$. The cells were then treated with curcumin and its analogues for $96 \mathrm{~h}$ (curcumin, A10, B10 and $\mathrm{C} 10$ at $1 \mu \mathrm{M}$; E10 and F10 at $0.5 \mu \mathrm{M}$ ). The number of viable cells was determined by a trypan blue exclusion assay. Apoptotic cells were determined by morphological assessment. Each value represents the mean \pm standard error from three separate experiments.

A

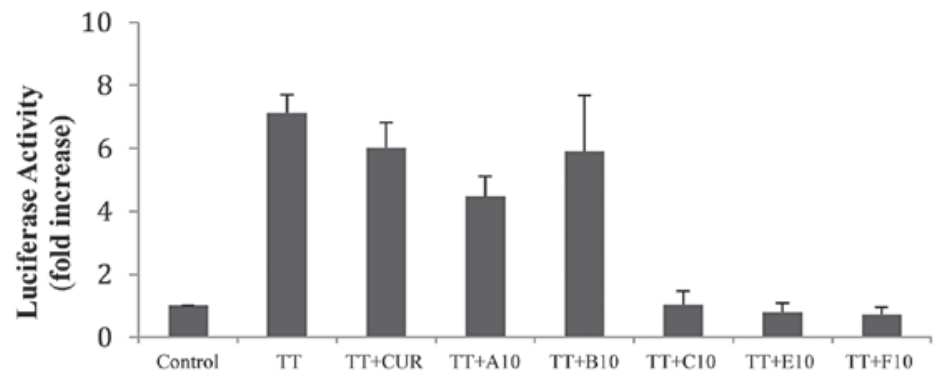

B

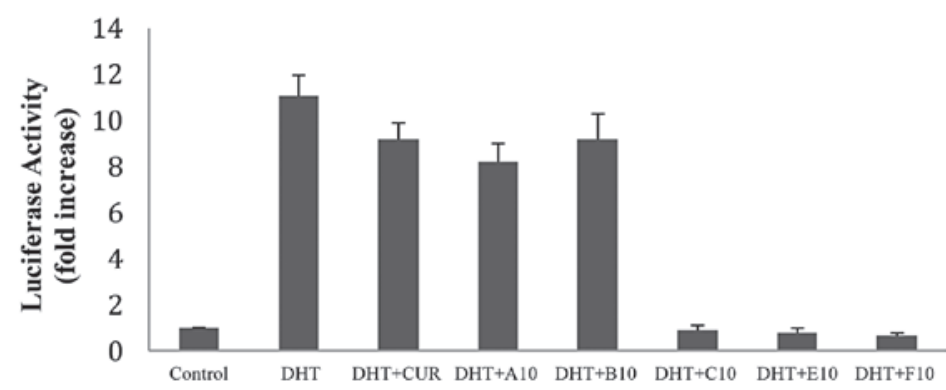

Figure 3. Effect of curcumin analogues on TT- or DHT-induced increase in androgen receptor reporter activity in CWR-22Rv1/AR cells: (A) for TT and (B) for DHT. The CWR-22Rv1/AR cells were seeded at a density of $1 \times 10^{4}$ cells $/ \mathrm{ml}$ of medium for $24 \mathrm{~h}$. The medium was then changed to RPMI without fetal bovine serum, and the cells were treated with vehicle (control) or with TT $(100 \mathrm{~nm})$ or DHT $(10 \mathrm{~nm})$ alone or in combination with curcumin and curcumin analogues $(1 \mu \mathrm{M})$ for $24 \mathrm{~h}$. The luciferase activity and protein concentration of the CWR-22Rv1/AR cells were measured. Each value represents the mean \pm standard error from three separate experiments. TT, testosterone; DHT, dihydrotestosterone; CUR, curcumin.

$24 \mathrm{~h}$, and the expression of PSA was analyzed by western blotting. As demonstrated in Fig. 4, treatment of CWR-22Rv1 and LNCaP cells with F10 and E10 resulted in a marked decrease in the level of PSA while the other compounds (curcumin, A10, $\mathrm{B} 10$ and $\mathrm{C} 10)$ were less active. The results indicate that the effects of E10, F10, A10 and C10 on CWR-22Rv1 and LNCaP cells were all associated with a decrease in PSA in TT- and DHT-induced cells. B10 was inactive.

\section{Discussion}

In the present study, it was identified that several curcumin analogues (A10, B10, C10, E10 and F10) exhibited stronger anticancer activities than curcumin in cultured human prostate cancer CWR-22Rv1 and LNCaP cells. Among the curcumin analogues, compounds F10 and E10 demonstrated a more potent inhibitory effect on the growth of CWR-22Rv1 and LNCaP 
A

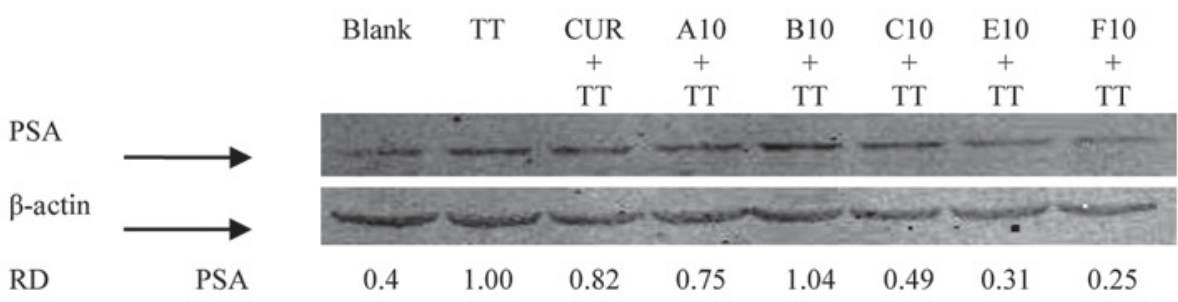

B

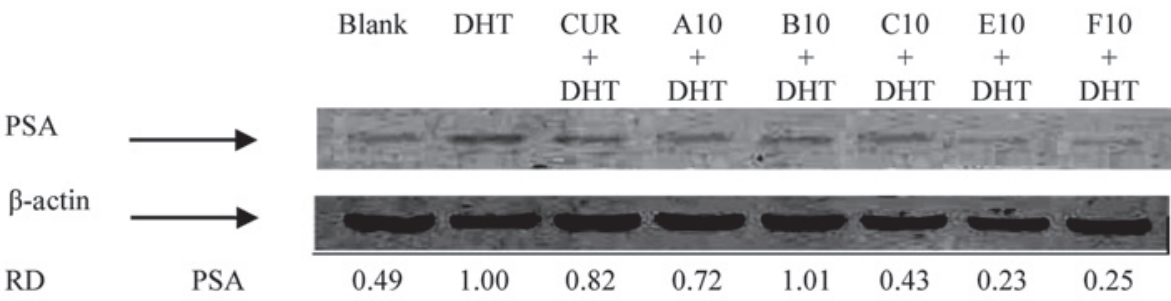

C

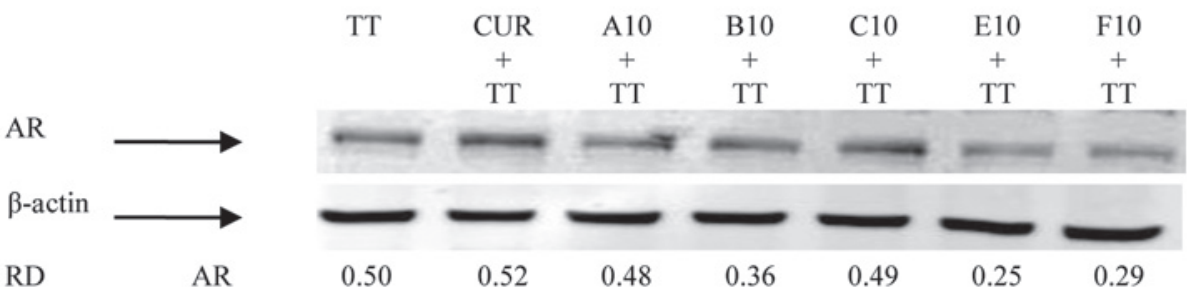

D

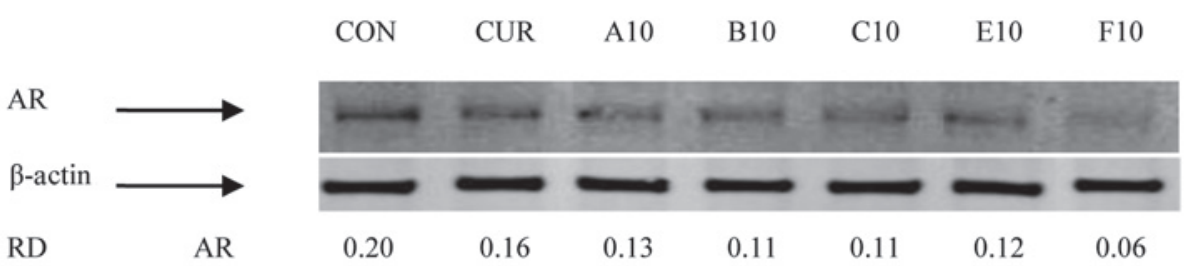

Figure 4. Effect of curcumin and its analogues on TT- and DHT-induced increase in PSA formation in the CWR-22Rv1 cells. (A) TT and (B) DHT. Effect of curcumin and its analogues on the activation of AR in CWR-22Rv1 and LNCaP cells. (C) CWR-22Rv1 and (D) LNCaP. The CWR-22Rv1 and LNCaP cells were seeded at a density of $1 \times 10^{4}$ cells $/ \mathrm{ml}$ of medium in $100 \mathrm{~mm}$ culture dishes $(10 \mathrm{ml} / \mathrm{dish})$ and incubated for $24 \mathrm{~h}$. The medium was changed to RPMI without fetal bovine serum, and the cells were then treated with vehicle, (A) $100 \mathrm{~nm}$ TT or (B) $10 \mathrm{~nm}$ alone or together with $1 \mu \mathrm{M}$ curcumin, A10, B10, C10, E10 or F10 for $24 \mathrm{~h}$. PSA was determined by western blot analysis with anti-PSA antibody. The extent of protein loading was determined by blotting for $\beta$-actin, and the levels of PSA in the western blots were analyzed by optical density measurements and normalized for $\beta$-actin to obtain the RD for the various samples. Representative blots from three experiments are demonstrated. TT, testosterone; DHT, dihydrotestosterone; PSA, prostate specific antigen; RD, relative optical density; CON, control; CUR, curcumin; AR, androgen receptor.
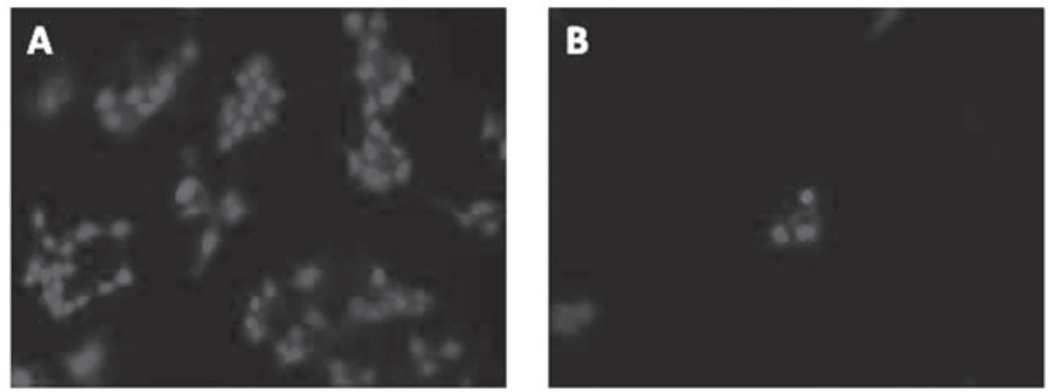

Figure 5. Effects of curcumin and its analogues on apoptosis of prostate cancer CWR-22Rv1 cells. Human prostate cancer CWR-22Rv1 cells were seeded at a density of $2 \times 10^{4}$ cells $/ \mathrm{ml}$ in $35 \mathrm{~mm}$ tissue culture dishes and incubated for $24 \mathrm{~h}$. The cells were then treated with curcumin and its analogues (curcumin, A10, $\mathrm{B} 10$ and $\mathrm{C} 10$ at $1 \mu \mathrm{M} ; \mathrm{E} 10$ and $\mathrm{F} 10$ at $0.5 \mu \mathrm{M})$. Apoptotic cells were determined by morphological assessment. Representative micrographs of (A) propidium iodide-stained control and (B) E10 at $0.5 \mu \mathrm{M}$ treated CWR-22Rv1 cells.

cells than any of the other curcumin analogues, and they also had higher stimulatory effects on apoptosis in CWR-22Rv1 cells compared with the other compounds (Fig. 5). In addi- tion, it was identified that all curcumin analogues examined (except for B10) were more potent inhibitors of AR in LNCaP and CWR-22Rv1 cells than curcumin. E10 and F10 were the 
most potent compounds among the five curcumin analogues examined for inhibiting the activation of AR.

The natural product curcumin (diferuloylmethane) has been demonstrated to inhibit numerous targets in prostate epithelial cells with an importance in cancer formation and progression. Among these targets are transcription factors, receptors, intracellular kinases, cytokines and growth factors (26). The effect of curcumin on the AR and on its target PSA has been demonstrated by several independent investigators using both endogenously expressed AR in LNCaP cells and ectopically expressed AR in PC-3 cells $(27,28)$. However, in these studies, curcumin was used at relatively high concentrations, typically at $>20 \mu \mathrm{M}$. It has previously been reported that curcumin has poor bioavailability, which has been determined in animal models and humans (29). This limitation has led researchers to generate a variety of synthetic analogues of curcumin and to investigate their capability to affect a number of molecular pathways implicated in tumorigenesis and cancer progression (30-33). Typical structure modifications include the introduction of substituents on the phenyl rings and modifications of the length of the linker between the phenyl rings. A specific group of such analogues has been exploited for their ability to inhibit AR function (34), and a number of these agents have been demonstrated to inhibit the expression of AR (35).

The present study determined the inhibitory effects of different curcumin analogues on TT- and DHT-induced activation of AR in CWR-22Rv1 cells. The results indicate that the different curcumin analogues had a similar effect on TT- or DHT-induced AR activation.

Based on the analysis of the association between the structures of curcumin-related compounds and their ability to inhibit the growth of cultured cancer cells, the presence of groups on the linker between the same aromatic rings was found to have a key role in determining the anticancer activity of the various analogues. Among the different series of curcumin-related compounds, linear or cyclic linkers between the two aromatic rings of curcumin-related compounds demonstrated different activity trends. In general, the compounds with a tetrahydrothiopyran-4-one (F10) or a tetrahydropyran-4-one (E10) linker exhibited the strongest activity, and compounds with an acetone linker (C10) exhibited moderate activity whereas compounds with a cyclohexanone linker (A10) or a cyclopentanone linker (B10), were less active. The activities of compounds with a heteroatom linker (E10 and F10) demonstrated improved effects compared with those without a heteroatom linker (A10, B10 and C10), which suggests that flexibility of curcumin-like compounds may enhance their antitumor activities by having interactions with the DNA of cancer cells and disrupting the activity of transcription factors, such as AR. Compounds with a small and highly rigid linker should be less active as previously described $(36,37)$. The results indicate that one of the potential mechanisms for the anticancer effect of curcumin analogues was inhibition of AR pathways in human prostate cancer cells.

\section{Acknowledgements}

The present study was supported by the 2011 Guangdong Province Leadership Grant, China National Science Foundation
Grants (grant no. 81272452 and 21272043), and by department funds from the Department of Chemical Biology in the Ernest Mario School of Pharmacy at Rutgers University (Piscataway, NJ, USA).

\section{References}

1. Siegel R, Ward E, Brawley O and Jemal A: Cancer statistics, 2011: the impact of eliminating socioeconomic and racial disparities on premature cancer deaths. CA Cancer J Clin 61: 212-236, 2011

2. Gao W, Bohl CE and Dalton JT: Chemistry and structural biology of androgen receptor. Chem Rev 105: 3352-3370, 2005.

3. Heinlein CA and Chang C: Androgen receptor in prostate cancer. Endocr Rev 25: 276-308, 2004.

4. Klotz L: Hormone therapy for patients with prostate carcinoma. Cancer 88 (Suppl): 3009-3014, 2000.

5. Simmons MN, Klein EA: Combined androgen blockade revisited: Emerging options for the treatment of castration-resistant prostate cancer. Urology 73: 697-705, 2009.

6. Kuttan R, Bhanumathy P, Nirmala K, et al: Potential anticancer activity of turmeric (Curcuma longa). Cancer Lett 29: 197-202, 1985.

7. HuangMT,SmartRC,WongCQ,etal:Inhibitory effect of curcumin, chlorogenic acid, caffeic acid, and ferulic acid on tumor promotion in mouse skin by 12-O-tetradecanoylphorbol-13-acetate. Cancer Res 48: 5941-5946, 1988.

8. Huang MT, Wang ZY, Georgiadis CA, et al: Inhibitory effects of curcumin on tumor initiation by benzo[a]pyrene and 7 , 12-dimethylbenz[a]anthracene. Carcinogenesis 13: 2183-2186, 1992.

9. Huang MT, Lou YR, Ma W, et al: Inhibitory effects of dietary curcumin on forestomach duodenal, and colon carcinogenesis in mice. Cancer Res 54: 5841-5847, 1994.

10. Rao CV, Rivenson A, Simi B, et al: Chemoprevention of colon carcinogenesis by dietary curcumin, a naturally occurring plant phenolic compound. Cancer Res 55: 259-266, 1995.

11. Leite KR, Chade DC, Sanudo A, et al: Effects of curcumin in an orthotopic murine bladder tumor model. Int Braz J Urol 35: 599-606, 2009.

12. Agrawal DK and Mishra PK: Curcumin and its analogues: potential anticancer agents. Med Res Rev 30: 818-860, 2010.

13. Kunnumakkara AB, Anand P and Aggarwal BB: Curcumin inhibits proliferation, invasion, angiogenesis and metastasis of different cancers through interaction with multiple cell signaling proteins. Cancer Lett 269: 199-225, 2008.

14. Teiten MH, Gaascht F, Eifes S, et al: Chemopreventive potential of curcumin in prostate cancer. Genes Nutr 5: 61-74, 2010.

15. Bill MA, Bakan C, Benson DM Jr, et al: Curcumin induces proapoptotic effects against human melanoma cells and modulates the cellular response to immunotherapeutic cytokines. Mol Cancer Ther 8: 2726-2735, 2009.

16. Johnson SM, Gulhati P, Arrieta I, et al: Curcumin inhibits proliferation of colorectal carcinoma by modulating Akt/mTOR signaling. Anticancer Res 29: 3185-3190, 2009.

17. Piantino CB, Salvadori FA, Ayres PP, et al: An evaluation of the anti-neoplastic activity of curcumin in prostate cancer cell lines. Int Braz J Urol 35: 354-360, 2009.

18. Kuo CT, Chen BC, Yu CC, et al: Apoptosis signal-regulating kinase 1 mediates denbinobin-induced apoptosis in human lung adenocarcinoma cells. J Biomed Sci 16: 43, 2009.

19. Sahu RP, Batra S, Srivastava SK: Activation of ATM/Chk1 by curcumin causes cell cycle arrest and apoptosis in human pancreatic cancer cells. Br J Cancer 100: 1425-1433, 2009.

20. Thangapazham RL, Sharma A and Maheshwari RK: Multiple molecular targets in cancer chemoprevention by curcumin. AAPS J 8: E443-E449, 2006.

21. Anand P, Sundaram C, Jhurani S, et al: Curcumin and cancer: an 'old-age' disease with an 'age-old' solution. Cancer Lett 267: 133-164, 2008.

22. Dhillon N, Aggarwal BB, Newman RA, et al: Phase II trial of curcumin in patients with advanced pancreatic cancer. Clin Cancer Res 14: 4491-4499, 2008.

23. Cheng AL, Hsu CH, Lin JK, et al: Phase I clinical trial of curcumin, a chemopreventive agent, in patients with high-risk or pre-malignant lesions. Anticancer Res 21: 2895-2900, 2001.

24. Wei X, Du ZY, Zheng X, et al: Synthesis and evaluation of curcumin-related compounds for anticancer activity. Eur J Med Chem 53: 235-245, 2012. 
25. Zheng X, Chang RL, Cui XX, et al: Inhibitory effect of 12-O-tetradecanoylphorbol-13-acetate alone or in combination with all-trans-retinoic acid on the growth of $\mathrm{LNCaP}$ prostate tumors in immunodeficient mice. Cancer Res 64: 1811-1820, 2004.

26. Aggarwal BB: Prostate cancer and curcumin: add spice to your life. Cancer Biol Ther 7: 1436-1440, 2008.

27. Nakamura K, Yasunaga Y, Segawa T, et al: Curcumin down-regulates AR gene expression and activation in prostate cancer cell lines. Int J Oncol 21: 825-830, 2002.

28. Tsui KH, Feng TH, Lin CM, et al: Curcumin blocks the activation of androgen and interlukin- 6 on prostate specific antigen expression in human prostatic carcinoma cells. J Androl 29: 661-668, 2008

29. Anand P, Kunnumakkara AB, Newman RA, et al: Bioavailability of curcumin: Problems and promises. Mol Pharm 4: 807-818, 2007.

30. Adams BK, Ferstl EM, Davis MC, et al: Synthesis and biological evaluation of novel curcumin analogs as anti-cancer and antiangiogenesis agents. Bioorg Med Chem 12: 3871-3883, 2004.

31. Basile V, Ferrari E, Lazzari S, et al: Curcumin derivatives: molecular basis of their anti-cancer activity. Biochem Pharmacol 78: 1305-1315, 2009.
32. Ishida J, Ohtsu H, Tachibana Y, et al: Antitumor agents. Part 214: synthesis and evaluation of curcumin analogues as cytotoxic agents. Bioorg Med Chem 10: 3481-3487, 2002.

33. Ohori H, Yamakoshi H, Tomizawa M, et al: Synthesis and biological analysis of new curcumin analogues bearing an enhanced potential for the medicinal treatment of cancer. Mol Cancer Ther 5: 2563-2571, 2006.

34. Zhou J, Geng G, Shi Q, et al: Design and synthesis of androgen receptor antagonists with bulky side chains for overcoming antiandrogen resistance. J Med Chem 52: 5546-5550, 2009.

35. Shi Q, Shih CC, Lee KH: Novel anti-prostate cancer curcumin analogues that enhance androgen receptor degradation activity. Anticancer Agents Med Chem 9: 904-912, 2009.

36. Zsila F, Bikadi Z and Simonyi M: Circular dichroism spectroscopic studies reveal $\mathrm{pH}$ dependent binding of curcumin in the minor groove of natural and synthetic nucleic acids. Org Biomol Chem 2: 2902-2910, 2004.

37. Caruso F, Rossi M, Benson A, et al: Ruthenium-arene complexes of curcumin: X-ray and density functional theory structure, synthesis, and spectroscopic characterization, in vitro antitumor activity, and DNA docking studies of (p-Cymene) Ru (curcuminato) chloro. J Med Chem 55: 1072-1081, 2012. 